\title{
Using participatory modeling processes to identify sources of climate risk in West Africa
}

\author{
Laura Schmitt Olabisi ${ }^{1}$ ( $)$ Saweda Liverpool-Tasie ${ }^{2} \cdot$ Louie Rivers III $^{3}$. \\ Arika Ligmann-Zielinska ${ }^{4} \cdot$ Jing Du $^{5} \cdot$ Riva Denny $^{6} \cdot$ Sandra Marquart-Pyatt $^{6}$. \\ Amadou Sidibé ${ }^{7,8}$
}

(C) Springer Science+Business Media, LLC 2017

\begin{abstract}
Participatory modeling has been widely recognized in recent years as a powerful tool for dealing with risk and uncertainty. By incorporating multiple perspectives into the structure of a model, we hypothesize that sources of risk can be identified and analyzed more comprehensively compared to traditional 'expert-driven' models. However, one of the weaknesses of a participatory modeling process is that it is typically not feasible to involve more than a few dozen people in model creation, and valuable perspectives on sources of risk may therefore be absent. We sought to address this weakness by conducting parallel participatory modeling processes in three countries in West Africa with
\end{abstract}

Laura Schmitt Olabisi

schmi420@msu.edu

1 Department of Community Sustainability, Michigan State University, 151 Natural Resources, East Lansing, MI 48824, USA

2 Department of Agricultural, Food and Resource Economics, Morrill Hall of Agriculture, Michigan State University, East Lansing, MI 48824, USA

3 Department of Forestry and Environmental Resources, North Carolina State University, Jordan Hall Addition 2219, Raleigh, NC 27695, USA

4 Geography Department, Michigan State University, 673 Auditorium Rd Room 121, East Lansing, MI 48824, USA

5 Department of Construction Science, Texas A \& M University, Francis Hall 333, College Station, TX 77843, USA

6 Department of Sociology, Michigan State University, 317 Berkey Hall, East Lansing, MI 48824, USA

7 International Crops Research Institute for the Semi-Arid Tropics, Samanko, Mali

8 Institut Polytechnique Rural de Formation et de Recherche Appliquée de Katibougou, BP06, Koulikoro, Mali similar climates and smallholder agricultural systems, but widely differing political and cultural contexts. Stakeholders involved in the agricultural sector in Ghana, Mali, and Nigeria participated in either a scenario planning process or a causal loop diagramming process, in which they were asked about drivers of agricultural productivity and food security, and sources of risk, including climate risk, between the present and mid-century (2035-2050). Participants in all three workshops identified both direct and indirect sources of climate risk, as they interact with other critical drivers of agricultural systems change, such as water availability, political investment in agriculture, and land availability. We conclude that participatory systems methods are a valuable addition to the suite of methodologies for analyzing climate risk and that scientists and policy-makers would do well to consider dynamic interactions between drivers of risk when assessing the resilience of agricultural systems to climate change.

Keywords Participatory modeling · Food security - West Africa $\cdot$ System dynamics $\cdot$ Scenarios

\section{Introduction}

\subsection{Climate risk and agricultural systems in West Africa}

West Africa is expected to be one of the global regions hit hardest by climate change, and in particular the agricultural sector faces risks to production and yields (Schlenker and Lobell 2010). Global climate models coupled with crop production models forecast a range of lower yields by 2050 as a result of climate change, with more severe yield reductions occurring in the period between 2030 and 2050 (Roudier 
et al. 2011; Ittersum et al. 2016). Higher temperatures which increase evapotranspiration and therefore water stress in crops are the dominant mechanism by which yields would be reduced under climate change (Lobell et al. 2011).

Precipitation shifts under climate change are more uncertain, with some regional climate models anticipating decreased overall rainfall in West Africa under climate change, and others demonstrating increased annual rainfall (Paeth et al. 2011). Currently, West Africa is experiencing an increase in annual precipitation from historic lows in the 1970's and 1980's, which is more pronounced in the Sahelian zone than the Guinean zone (Sanogo et al. 2015). Recent studies have indicated decreased rainfall during the growing season and a delayed rainy season onset may be shortening the growing season, but it is unclear whether this pattern is linked to anthropogenic climate change (Mertz et al. 2012). Even with the uncertainty around average rainfall patterns, climate models indicate that extreme events, such as droughts and floods, could become more common under climate change (Abiodun et al. 2013). Droughts historically have had a negative impact on crop yields throughout the Sahel (Boubacar 2010).

In addition to lower yields, climate change could impact agriculture in West Africa through inducing migration or aggravating existing natural resource conflicts (Obioha 2008). Pest and disease outbreaks are another climate change-associated risk, although empirical data from West Africa on this topic are extremely limited (Todd et al. 2002; Gregory et al. 2009).

West Africa is also undergoing changes in other sectors, including the world's highest rate of urbanization (Parnell and Walawege 2011), high levels of population growth, changes in food demand and consumption patterns (Zhou and Staatz 2016), land use change, and environmental degradation (Yu et al. 2016). All of these trends could exacerbate climate risks in dynamic and nonlinear ways.

These scientific studies collectively paint a troubling picture of the future of the agricultural sector in West Africa under climate change, but there is a relative paucity of data on the ground around how these modeled changes are playing out in a local environment, and how communities might respond. In order to prioritize adaptation interventions in response to these risks, a participatory risk assessment approach which incorporates local expert knowledge is desirable.

\subsection{Participatory modeling for climate risk assessment}

In recent years, participatory assessment methods have drawn attention for their ability to bring local expert knowledge together with expert-driven analysis of climate risk, such as climate models, in order to facilitate localized adaptation strategies (Aalst et al. 2008). Participatory risk assessment may be considered a branch of participatory integrated assessment, which is still a very young field with relatively few case study applications (Salter et al. 2010). Its underlying philosophy is one of the incorporating diverse sources of knowledge to generate more robust scientific conclusions, in the context of the 'wicked' or 'messy' problems which characterize the sustainability science and planning space (Clark and Dickson 2003). Both scenarios and modeling tools have been used in participatory assessment processes, including by Royal Dutch Shell (Kahane 2012) and in European water planning (Newig et al. 2008). However, these participatory assessment methods seem not to have been well integrated into assessments explicitly focused on analyzing future climate risks, risk mitigation, and tradeoffs. Some examples of participatory risk assessment methods include transect walks, risk mapping, and calendars of seasonal risk (Webber and Hill 2014). These tools are appropriate and useful for assessing immediate risk, but they may be less useful for investigating medium-to-long-term risks as they interact in a dynamic environment. Two methods for planning in environmental systems, which may be applied to climate risk assessment, are transformative scenario planning and causal loop diagramming.

\subsubsection{Transformative scenario planning}

Transformative scenario planning (TSP) was designed to help communities develop strategies for resilience under highly uncertain future conditions (Kahane 2012). A scenario is a 'structured account of a possible future' (Peterson et al. 2003, p. 360), which describes a plausible outcome, rather than a statistically derived prediction. TSP is a participatory process in which scenarios are generated by stakeholders themselves, and it is a method that is uniquely wellsuited to participatory planning and group exploration of the future of a complex system for that reason (Kok et al. 2011). In the context of climate change, another advantage of TSP is in its explicit inclusion of unpredictable and uncontrollable 'game-changing' events, thereby incorporating some of the threshold effects and nonlinearity which are likely to affect agricultural systems under climate change. Scenario planning has been used in African agricultural systems to generate development strategies in Tanzania (Enfors et al. 2008) and to generate food security and climate change adaptation strategies in West and East Africa under the Consultative Group on International Agricultural Research (CGIAR) Future Scenarios research team (Vervoort et al. 2014).

\subsubsection{Causal loop diagramming}

Causal loop diagramming (CLD) is a qualitative modeling method used in system dynamics to identify causal 
relationships between variables and feedback mechanisms (Schmitt Olabisi 2010). System dynamics is a field of modeling used since the 1960's to address problems that involve feedback, nonlinear dynamics, uncertainty, and time delays (Legasto et al. 1980). In recent decades, researchers have been using system dynamics in a participatory manner, involving stakeholders and local experts in the model-building process. This technique has several advantages, including the incorporation of local knowledge into the model; achieving 'buy-in' from stakeholders and policy-makers who will be in charge of implementing the model's recommendations; and providing opportunities for social learning among the modelers and stakeholders as they jointly discuss complex problems in a systemic way (Stave 2002; Van den Belt 2004; Schmitt Olabisi et al. 2010). In spite of all of these advantages of a participatory system dynamics modeling approach, this technique has not been used to a great extent in agricultural systems, or for climate risk assessment.

We used transformative scenario planning in Mali and Ghana and causal loop diagramming in Nigeria to engage local experts in a climate risk assessment exercise focused on agricultural systems. The research questions we wished to address through this study are as follows:

1. What are the most important risks of climate change to agricultural systems in West Africa over the medium term (mid-century)?

2. How do these risks of climate change to agricultural production interact with other sources of environmental/ agricultural risk?

3. What are the relative strengths and weaknesses of transformative scenario planning and causal loop diagramming as participatory risk assessment methods?

\section{Methods}

\subsection{Description of study area}

The region described in this study encompasses both the Sahel and the tropical savanna zones of dryland West Africa. In Ghana and Mali, the workshops took place in Lawra, where rainfall varies between 523 and $1036 \mathrm{~mm} /$ year and in Koutiala, where annual rainfall typically varies between 750 and $900 \mathrm{~mm}$. In Nigeria, the workshop took place in Ibadan, where annual rainfall is around $500 \mathrm{~mm} /$ year. However, participants in the Nigeria workshop were drawn from around the country, including the drier north. For the purposes of comparison within similar climatic zones, only the workshop results from Northern Nigeria are discussed in this paper.

The three countries also differ considerably by population density, with Mali having the lowest density at 13.27 people/sq. km, and Nigeria having the highest density at 191.8 people/sq. km. Ghana is in between at 108 people/ sq. km. Nigeria is the most populous country in Africa, and both Nigeria and Ghana are highly urbanized (48 and $54 \%$ of their populations live in cities, respectively), while Mali is more rural (only 40\% urban) (World Bank 2017). Moreover, agricultural households in Mali tend to be large and polygamous, resulting in an average household size of 6 persons/household (Ibisomi and Wet 2014), while average household size in Nigeria is 5 persons (National Population Commission 2014). Ghana is characterized by nuclear family households, and average household size is 4.4 persons (Ghana Statistical Service 2012). These different population patterns affect both the actual and perceived population pressure on land and water resources in the three countries, as well as land tenure systems.

Governance around both climate change and agriculture is another critical piece of context in the three countries. Stagnant yields of staple crops in Nigeria are frequently blamed on a lack of government investment or interest in agriculture, given the country's dependence on oil revenue (although falling oil prices in recent years have rekindled attention to the agricultural sector). For this reason, in Nigeria the share of value-added agricultural products in total GDP in 2014 was the lowest of the three countries at 20.2\%, according to the World Bank. Dependence on agriculture was highest in Mali, where it constituted $40.4 \%$ of GDP, while in Ghana it was 22.4\% of GDP (World Bank 2017).

Nigeria's governance system is highly decentralized to the states, which have significant jurisdiction over agricultural policy. In contrast, Malian agricultural policy is set predominantly at the national level, and parastatal cotton companies have also played a major role in agricultural development in the Koutiala district (Géronimi et al. 2005). All three countries have expressed concern over climate change, primarily from an adaptation standpoint, as (with the exception of the Nigerian oil sector) their contributions to global greenhouse gas emissions are virtually nil (Oladipo 2010).

While we cannot claim that the three countries represent the full diversity of West African agriculture, they do present fairly distinct socio-ecological systems contained within a similar climatic transect. As such, exercises in Mali, Ghana, and Nigeria are expected to showcase a wide range of potential risk mitigation and adaptation 'spaces' within the West African context. They were chosen as focal countries for this reason under both the Adaptation at Scale in Semi-Arid Regions project (ASSAR) and the USAID-funded Nigeria Agricultural Policy Project, as described below.

\subsection{Description of workshops}

The workshops were conducted in Mali and Ghana under the activities of the Adaptation at Scale in Semi-Arid Regions 
(ASSAR) project, an interdisciplinary research initiative which looks at the drivers of vulnerability and adaptation to climatic and non-climatic risks in semi-arid regions of Asia and Africa. It covers 3 regions in Africa inclusive of West Africa, Eastern Africa, and Southern Africa and part of India. In Nigeria, the workshop was organized under the Nigeria Agricultural Policy Project, funded by USAID, whose aim is to strengthen evidence-based policy in the agricultural sector at both state and federal levels. All three workshops took place between June and September 2016.

Participants in each workshop were recruited by in-country researchers working with these respective projects. Each workshop hosted between 20 and 30 participants. In Mali and Ghana, participants represented the Koutiala and Lawra districts specifically, while in Nigeria they were drawn from around the country. The workshop participants were intended to represent a cross section of those involved with the agricultural sector, including extension workers, academics, representatives of farmer organizations, representatives from development and agricultural non-profit organizations, private sector input suppliers, local elected officials, traditional leaders, and government scientists. Travel expenses were reimbursed for participants, and their meals and lodging were provided on the site of the workshop. Informed consent was obtained from all workshop participants prior to their responses being used in the research study.

\subsubsection{Ghana and Mali scenarios}

In Ghana and Mali, transformative scenario planning was used to elicit multiple stories of the future with the aim of developing policy actions in the present to enhance resilience of the agricultural sector. This methodology is described at length in (Kahane 2012). The process began by identifying influential drivers of change which are operating in regional agricultural systems and are likely to shape these systems into the future. (2035 was chosen as an endpoint for this exercise, because it represents approximately one generation into the future, in order to encourage the participants to envision their children/grandchildren living as adults in a particular scenario.) Participants brainstormed drivers of change and then voted for the top two most influential drivers, which were used to construct the scenario 'axes.' Drivers which received a lot of votes (e.g., more than five), but which were not one of the top two vote-getters, were lifted up by the facilitator as potential confounding factors to be considered in the scenario construction. Scenario axes representing the two top drivers divided the scenario space into quadrants, with four possible combinations of the driver states in 2035: low-low, low-high, high-low, and high-high. These four spaces represented the four scenarios which were constructed around the focal question, 'What do our agricultural systems and rural livelihoods look like in the year
2035?' Participants were then divided into four groups-one for each scenario-and asked to construct plausible stories around this focal question, given the driver state they were assigned for 2035. Groups sketched out a timeline of events leading to the 2035 scenario, to ensure a plausible, causal mechanism for agricultural systems being transformed beginning in the present and proceeding to 2035. This timeline could include driver trends, but also unexpected or 'surprising' events such as opposition political parties gaining power, major droughts, or in-migration from neighboring countries. The consideration of disruptive events is part of what gives scenario exercises their power over more conventional analyses (Schmitt Olabisi 2010).

The scenarios were presented in a large-group setting and captured in written form by note-takers. After the conclusion of the workshop, the scenarios were further developed with the participation of all workshop attendees (those without access to computers were visited in person by members of the in-country scenario team, to get their feedback on the written document). The scenario document for each country went through multiple iterations designed to make each scenario more internally consistent and holistic and to clarify points raised in the workshop. This scenario document formed the basis for our content analysis around climate change. The document was coded for any mention of 'climate change,' 'shifting weather,' 'shifting precipitation,' 'increased drought,' 'increased flooding,' and 'heat.' We also read the document carefully for any mention of indirect effects of climate change. The Ghanaian scenario document was produced in English, while the Malian document was in French.

\subsubsection{Nigeria CLD mapping}

In Nigeria, we used a causal loop diagramming (CLD) technique to lead workshop participants through an exercise in which they drew diagrams depicting the barriers to, and opportunities for, Nigerian agricultural productivity between the present and 2050. A total of 11 groups were formed at the workshop, representing five regions of the country (northwest, north central, southeast, southwest, and south south), with no more than six participants per group. Because the majority of participants were from the Southeast and Southwest regions, there were three and four groups diagramming these regions, respectively, to avoid groups that were too large to sustain inclusive discussion. For the purposes of this study, to compare regions that are more climatically similar, we will focus on the diagrams drawn by the North Central and Northwest groups.

Following the development of the CLDs, the groups were asked to represent on their diagrams climate change impacts they are currently seeing in their region, as well as climate impacts they are concerned about leading up 
to mid-century. The groups then presented their diagrams to one another in a general group discussion. This served to clarify the meaning behind ambiguous variables and linkages, answer questions about the causal logic behind the diagrams, and compare and contrast diagrams made by different groups. The modeling team collected all diagrams and notes at the end of the workshop. Climate change impacts mentioned by the groups were noted as direct (having a direct effect on agricultural production or yields) or indirect (having an effect on agricultural production or yields mediated by another variable).

\section{Results and discussion}

\subsection{Scenarios}

Workshop participants developed four scenarios in each workshop in Mali and northern Ghana. As described above, these scenario spaces were defined by their position along each of two driver axes. In Mali, these drivers were 'access to land' and 'access to water' (Table 1). In Ghana, these drivers were 'access to water' and 'political commitment' (Table 2). Other factors which played a prominent role in shaping the agricultural sector, according to stakeholders in Mali, were private investment in agriculture, public investment in infrastructure, non-governmental organization involvement in development, degree of local control over resources, and conflicts between farmers and pastoralists. In Ghana, infrastructure development, involvement of traditional authorities and NGOs in development, private sector investment, mining and petroleum development, and management of natural resources were all seen as important drivers of change into the year 2035.

Neither set of workshop participants described climate change as a major driver affecting the future of the agricultural sector by 2035 , but in both countries climate change impacts were described in the scenario narratives. In the scenario 'Geleya Dugu,' characterized by poor access to land and water, workshop participants described climatic variability as becoming more intense, leading to longer droughts and prompting the government to promote integrated cropagroforestry-livestock management to compensate. In the Ghana 'Bekpeebe' scenario, characterized by low access to water and low political commitment to agriculture, participants envisioned a decline in overall rainfall amount and consequent drying of local water bodies. This would, in turn, lead to crop failure and political unrest in the neighboring country of Burkina Faso, prompting migration and potential conflict between migrants and long-term residents of Upper West Ghana. It is notable that in both Mali and Ghana, climate change was only mentioned explicitly in the scenarios describing poor conditions for resource access and

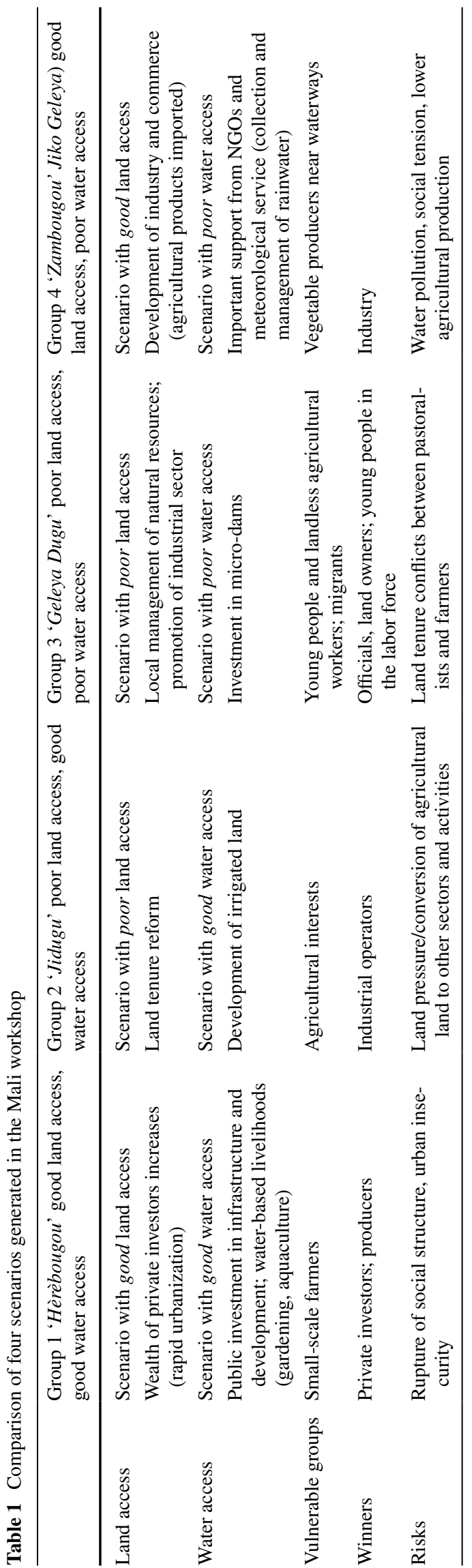


Table 2 Comparison of four scenarios generated in Ghana workshop

\begin{tabular}{|c|c|c|c|c|}
\hline & $\begin{array}{l}\text { Group } 1 \text { 'Azaabewei' (all is } \\
\text { not lost) }\end{array}$ & Group 2 'Nuoyong' all joy & $\begin{array}{l}\text { Group } 3 \text { 'Bekpeehe' } \\
\text { (orphans) }\end{array}$ & $\begin{array}{l}\text { Group } 4 \text { 'Zieliebe' (seasons } \\
\text { change) }\end{array}$ \\
\hline Access to water & $\begin{array}{l}\text { Local interventions for water } \\
\text { management }\end{array}$ & $\begin{array}{l}\text { Construction of a large water } \\
\text { dam (Kamba) } \\
\text { Sustainable use }\end{array}$ & $\begin{array}{l}\text { Local initiatives for water } \\
\text { management/depend- } \\
\text { ency for other uses (e.g., } \\
\text { hydropower) }\end{array}$ & $\begin{array}{l}\text { Natural sources and good } \\
\text { water management avail- } \\
\text { ability of water }\end{array}$ \\
\hline Political commitment & $\begin{array}{l}\text { High support for manage- } \\
\text { ment of resources } \\
\text { Large infrastructure (facto- } \\
\text { ries, roads) }\end{array}$ & $\begin{array}{l}\text { Increased support technol- } \\
\text { ogy }\end{array}$ & Strong traditional authorities & $\begin{array}{c}\text { Strong support from NGOs } \\
\text { and farmer organizations }\end{array}$ \\
\hline Vulnerable groups & Smallholder farmers & $\begin{array}{l}\text { Land owners in catchment } \\
\text { areas (for resettlement) }\end{array}$ & $\begin{array}{l}\text { Poor or elderly, those with- } \\
\text { out resources to mine } \\
\text { Immigrants }\end{array}$ & \\
\hline Gainers & Private sector & Smallholder farmers & Exploiters, extremist, miners & Community \\
\hline Risks & Social vices/disputes & $\begin{array}{l}\text { Flooding in catchments/ } \\
\text { conflicts }\end{array}$ & Regional conflicts & $\begin{array}{l}\text { Water pollution/conflicts } \\
\text { between farmers }\end{array}$ \\
\hline
\end{tabular}

agricultural development, implying that in scenarios with favorable conditions for agriculture, climate change would not be a major concern.

\subsection{Causal loop diagrams}

Stakeholder groups from the Northwest and North Central regions of Nigeria produced two causal loop diagrams depicting drivers of agricultural productivity (Figs. 1, 2).

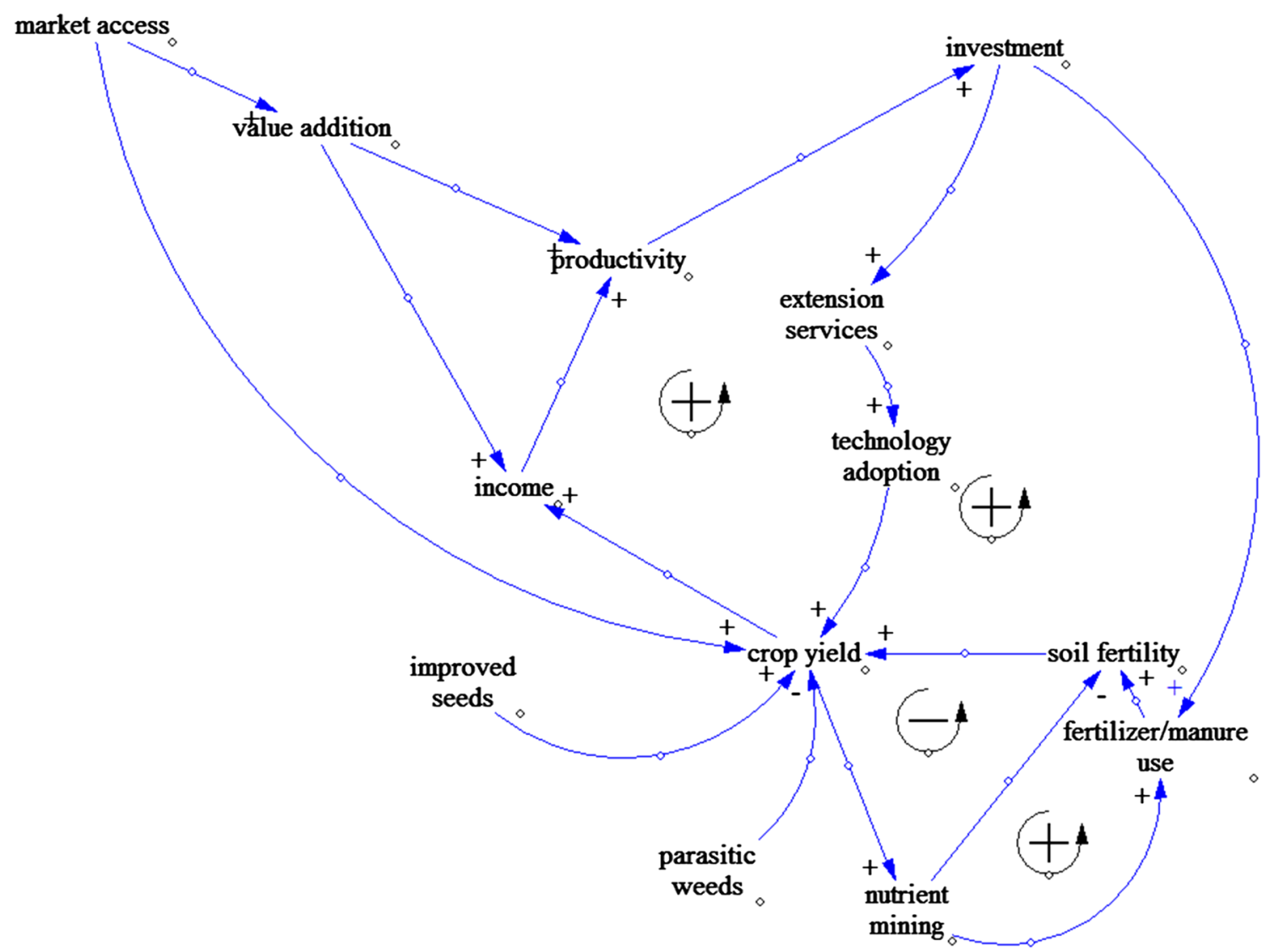

Fig. 1 Causal loop diagram created by participants from Northwest Nigeria, featuring three reinforcing feedback loops and one balancing feedback loop (described in the text) 


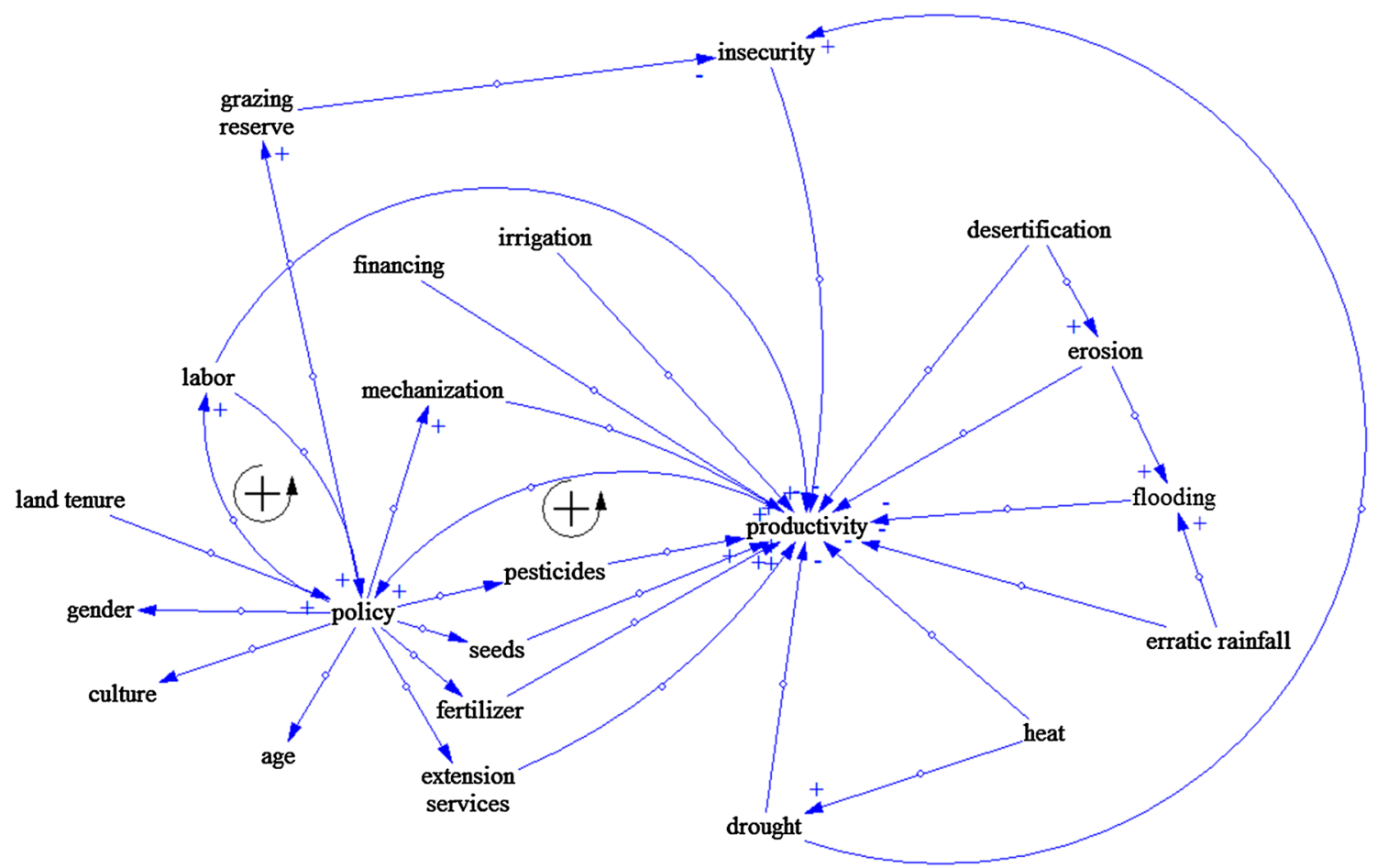

Fig. 2 Causal loop diagram created by participants from North Central Nigeria, featuring two reinforcing feedback loops (described in the text). Climate change impacts on production, both direct and indirect, may be seen on the left-hand side of the diagram

In causal loop diagramming, feedback loops are typically understood to be driving system behavior. The diagram for Northwest Nigeria featured three reinforcing feedback loops and one balancing feedback loop related to crop yields. The first concerns farmer productivity and reinvestment-as yields grow, farmer make more money and invest in inputs such as manure and fertilizer, further increasing yields. A second reinforcing feedback loop is similar-increased farmer income as the result of higher yields leads to more technology adoption on farm. The final reinforcing feedback loop and the balancing feedback loop both pertain to soil fertility, and they operate in opposition to one another. As land is intensively farmed, leading to higher yields, soil nutrient content declines, depressing yields. However, farmers may respond by increasing manure and fertilizer application, boosting yields in a reinforcing manner.

The diagram for North Central Nigeria contained two reinforcing loops, both pertaining to government agricultural policy, which stakeholders from this region saw as a critical driver of agricultural development (similar to northern Ghana). As agricultural policy support increases, so does the agricultural labor force-which then draws more policy support. Government support for agriculture also increases the inputs, financing, mechanization, and extension services available for agriculture, all of which boost productivity. With increased productivity, the agricultural sector gains political and economic clout, driving more political attention to itself in a reinforcing loop. In both Northwest and North Central Nigeria, it should be noted that these reinforcing loops may act in future to rapidly increase agricultural growth and development, but participants see them currently as keeping Nigerian agriculture in a low-productivity trap. In other words, low yields and low production are currently depressing investment and government attention that could potentially 'unlock' rapid agricultural growth.

Workshop participants in Northwest Nigeria did not explicitly discuss climate change. It should be noted that states in Northwest Nigeria border on the Niger River, and irrigation schemes play a role in boosting agricultural yields in this region. Participants from North Central Nigeria named multiple direct and indirect impacts of climate change on agriculture by mid-century. Heat and 'erratic rainfall' (defined in the large group discussion session as unpredictable onset of spring rains and of rainfall patterns within the growing season) were seen as having a direct impact on agricultural productivity. Flooding and drought, leading to 'insecurity' (migration and conflict), were seen as affected by heat and erratic rainfall, also leading indirectly to lower agricultural production. In large group discussions, participants agreed that while climate change may exacerbate desertification, it is also affected by poor land management. Ultimately, desertification was seen as leading to loss of productive agricultural/pastoral lands. 


\subsection{Climate risk assessment and proposed solutions}

Shifting rainfall patterns, both in terms of variability and overall amount, were seen as important climate change risks in all three countries, particularly in water-poor situations (such as the low water access scenarios in Mali and Ghana, and in water-stressed North Central Nigeria). In response, participants in the three workshops proposed schemes to more effectively collect and store water, such as the construction of dams, and better water management in agriculture, such as irrigation schemes and integrated croplivestock-agroforestry management, which has the potential to more tightly cycle nutrients and water on farm. In spite of these climate-related concerns, it is reasonable to conclude from the workshop output that participants in all three countries were more concerned about other drivers which are negatively affecting agricultural productivity, and could continue to do so in the future. These drivers include access to land, government attention to the agricultural sector, farmer access to inputs, and sustainable management of natural resources. This is understandable, because while the most severe impacts of climate change will likely not be felt until mid-century, these other drivers are causing the agricultural sector to undergo rapid transformation in the present. In spite of the emphasis on the future in all three workshops, participants are obviously concerned with things they already see happening. This presents an opportunity for scientists and policy-makers seeking climate adaptation solutions to tie in climate adaptation with other risks perceived by agricultural sector stakeholders, to gain traction and impact. For example, there has arguably been insufficient attention to effectiveness of agricultural inputs under altered climate regimes, or to the ways in which climate change could worsen water pollution. Traditional climate risk assessments, which center climate change rather than a systemic analysis of the agricultural sector, may miss some of these complex interactions.

Participants from North Central Nigeria did articulate multiple direct and indirect risks of climate change to agricultural systems. It is likely that these risks are relevant for climatically similar systems in Mali and Ghana as well, and there is some evidence of this in the scenario narratives. In both Ghana and Mali, increased conflict between pastoralists and farmers was mentioned as a future risk, although in Mali this was related to land access as a major driver, and in Ghana to erratic rainfall, crop failure, and in-migration from Burkina Faso. North Central Nigerian participants articulated a mechanism of conflict driven by drought, which could cause the productivity of grazing lands to fall. As a solution, they proposed sustainably managed grazing reserves, which could alleviate some of the conflict between displaced pastoralists and private landowners, which has been escalating in Nigeria in recent years (Conroy 2014).
The discussion of pastoralist-farmer conflicts highlights the interconnectedness of several drivers of agricultural change and indicates that climate change could worsen problems that are driven by land tenure changes and lack of water access. Currently, research on this issue in West Africa is sparse (Obioha 2008).

\subsection{Participatory methodologies for risk assessment}

Both transformative scenario planning and causal loop diagramming generated descriptions of climate risk that emphasized their interaction with other drivers of change, as well as a picture of how they would play out in the medium-term future under different conditions. Important 'confounding' variables were identified that might either exacerbate or mitigate climate risk, which is not always the case in more conventional climate risk assessments, whether expert driven or participatory. The causal loop diagramming process seemed to draw out these causal interactions more explicitly than the transformative scenario planning process. On the other hand, the scenario planning process painted more vivid pictures of the future and incorporated more 'surprising' events—such as massive in-migration from neighboring countries-than the CLD exercise. A combination of these two methodologies shows promise for leveraging both of their strengths (Schmitt Olabisi et al. 2010).

In all three workshop exercises, climate change was not the primary framing mechanism, although the projects which sponsored these workshops were focused on climate change. This was a deliberate choice, to avoid over-attribution of any agricultural issues to climate change. However, this may also have prevented participants from thinking about each aspect of the system in light of how it could possibly be affected by climate change. For example, water access was a critical part of the future of agriculture in both Mali and Ghana, but in only one scenario in each location was there any mention of how climate change could impact water access. A focus on the medium-term future (2035-2050) allowed for workshop participants' analysis to be grounded in current trends, but may have been too immediate for the most severe impacts of climate change to be recognized.

In terms of the relative strengths and weaknesses of the two approaches, scenario planning appeared to more effectively incorporate unanticipated events with the potential to change system trajectories, but sometimes faltered in describing explicit causal mechanisms for generating these outcomes. Causal loop diagramming gave the participants an explicit framework for reasoning through the ultimate and proximate causes of systems change, but was not as strong as the scenario process at painting a picture of multiple plausible futures, and strategies for resilience which could be effective in these futures. 
This study sought to identify climate risks in West Africa using participatory methodologies and to assess the relative strengths of these participatory methodologies. With few exceptions (e.g., (Palazzo et al. 2017), assessment of climate risk in the region has been very expert driven and top-down, using quantitative modeling techniques to assess the potential impacts of climate change on cropping systems at a large scale (Lobell et al. 2008; Schlenker and Lobell 2010). Without the active participation of those living in these systems, key sources of risk, and risk mitigation options, are likely to be missed or mis-identified. Our study represents an innovation in methodology for conducting climate risk assessment in Africa, particularly in comparing scenario planning with causal loop diagramming. Through these methods, stakeholders identified key vulnerabilities and adaptation options that have not been discussed extensively elsewhere in the climate adaptation literature (e.g., conflict between pastoralists and farmers; and how water access and climate change may interact at a local scale).

\section{Conclusions}

We pioneered two new techniques in participatory climate risk assessment-transformative scenario planning and causal loop diagramming - both of which showed promise for making climate risk assessment more holistic and linking climate risk to other sources of long-term change in the system of study. Scenario planning incorporated more potentially disruptive and surprising events into the risk assessment, which could help communities be more resilient to these events. Causal loop diagramming explicitly highlighted the causal mechanisms and interactions which are currently keeping agricultural production low in West Africa and which could become worse under climate change. A combination of these methods could harness the relative strengths of each. There is also an opportunity to develop a quantitative model to support risk assessment out of this exercise, using the CLD as the basis of a system dynamics model.

Water availability and management, political will and attention to agriculture, and land access were seen as critical drivers shaping the agricultural risk landscape for all three countries into the medium-term future. Participants spoke at more length about these drivers than about climate change, probably because they are not yet experiencing the most severe impacts of climate change in their regions, but they are experiencing these other stresses. Going forward, it will be important for both scientists and policy-makers to consider how climate change will interact with these drivers of change, and to communicate these interactions to stakeholders in the agricultural system.
Acknowledgements This study was funded by the National Science Foundation Directorate for Social, Behavioral and Economic Sciences (Grant No. 1416730), the USAID/Nigeria funded Food Security Policy Innovation Lab Associate Award, contract number AID1-620-LA-15-00001, and the Adaptation at Scale in Semi-Arid Regions program.

\section{References}

Aalst MKV, Cannon T, Burton I (2008) Community level adaptation to climate change: the potential role of participatory community risk assessment. Glob Environ Change 18:165-179

Abiodun BJ, Lawal KA, Salami AT, Abatan AA (2013) Potential influences of global warming on future climate and extreme events in Nigeria. Reg Environ Change 13:477-491

Boubacar I (2010). The effects of drought on crop yields and yield variability in Sahel. Southern agricultural economics association annual meeting, Orlando, FL, pp 1-30

Clark WC, Dickson NM (2003) Sustainability science: the emerging research program. PNAS 100(14):8059-8061

Conroy S (2014). Land conflicts and lethal violence in Nigeria: patterns, mapping and evolution (2006-2014). IFRA-Nigeria working papers series, Abuja, IFRA-Nigeria, vol 38

Enfors EI, Gordon LJ, Peterson GD, Bossio D (2008) Making investments in dryland development work: participatory scenario planning in the Makanya Catchment, Tanzania. Ecol Soc 13(2):42-61

Géronimi V, Diallo SB, Sidibé L (2005) Le franc malien: fausses ruptures et vraies discontinuités dans les relations franco-maliennes. In: Gemdev and Université du Mali (eds) Mali-France: regards croisés sur une histoire partagée. Donniya-Karthala, Bamako, Paris

Ghana Statistical Service (2012) 2010 population \& housing census summary report of final results. Ghana Statistical Service, Accra

Gregory PJ, Johnson SN, Newton AC, Ingram JS (2009) Integrating pests and pathogens into the climate change/food security debate. J Exp Bot 60(10):2827-2838

Ibisomi LDG, Wet ND (2014) The dynamics of household structure in Sub-Saharan Africa. In: Odimegwu CO, Kekovole J (eds) Continuity and change in Sub-Saharan African demography. Routledge, New York

Ittersum MKV, Bussel LGJV, Wolf J, Grassini P, Wart JV, Guilpart N, Claessens L, Groot HD, Wiebe K, Mason-D'Croz D, Yang H, Boogaard H, Oort PAJV, Loon MPV, Saito K, Adimo O, Adjei-Nsiah S, Agali A, Bala A, Chikowo R, Kaizzi K, Kouressy M, Makoi JHJR, Ouattara K, Tesfaye K, Cassman KG (2016) Can sub-Saharan Africa feed itself? Proc Natl Acad Sci 113(52):14964-14969

Kahane A (2012) Transformative scenario planning: working together to change the future. Berrett-Koehler Publishers, San Francisco

Kok K, Vliet M, Bärlund I, Dubel A, Sendzimir J (2011) Combining participative backcasting and exploratory scenario development: experiences from the SCENES project. Technol Forecast Soc 78(5):835-851

Legasto A, Forrester JW, Lyneis JM (1980) System dynamics. NorthHolland Pub. Co., Elsevier/North-Holland, Amsterdam, New York

Lobell DB, Burke MB, Tebaldi C, Mastrandrea MD, Falcon WP, Naylor RL (2008) Prioritizing climate change adaptation needs for food security in 2030. Science 319(5863):607-610

Lobell DB, Bänziger M, Magorokosho C, Vivek B (2011) Nonlinear heat effects on African maize as evidenced by historical yield trials. Nat Clim Change 1:42-45

Mertz O, D'haen S, Maiga A, Moussa IB, Barbier B, Diouf A, Diallo D, Da ED, Dabi D (2012) Climate variability and 
environmental stress in the Sudan-Sahel zone of West Africa. Ambio 41(4):380-392

National Population Commission (2014) Nigeria demographic and health survey 2013. ICF International, Rockville

Newig J, Haberl H, Pahl-Wostl C, Rothman DS (2008) Formalised and non-formalised methods in resource management-knowledge and social learning in participatory processes: an introduction. Syst Pract Act Res 21(6):381-387

Obioha EE (2008) Climate change, population drift and violent conflict over land resources in northeastern Nigeria. J Hum Ecol 23(4):311-324

Oladipo E (2010) Towards enhancing the adaptive capacity of Nigeria: a review of the country's state of preparedness for climate change adaptation. Henrich Boll Foundation, Ilorin

Paeth H, Hall NMJ, Gaertner MA, Alonso MD, Moumouni S, Polcher J, Ruti PM, Fink AH, Gosset M, Lebel T, Gaye AT, Rowell DP, Moufouma-Okia W, Jacob D, Rockel B, Giorgi F, Rummukainen M (2011) Progress in regional downscaling of west African Precipitation. Atmos Sci Lett 12(2011):75-82

Palazzo A, Vervoort JM, Mason-D’Croz D, Rutting L, Havlík P, Islam S, Bayala J, Valin H, Kadi HAK, Thornton P, Zougmore R (2017) Linking regional stakeholder scenarios and shared socioeconomic pathways: quantified West African food and climate futures in a global context. Glob Environ Change 45:227-242

Parnell S, Walawege R (2011) Sub-Saharan African urbanisation and global environmental change. Glob Environ Change Hum Policy Dimens 21:S12-S20

Peterson GD, Cumming GS, Carpenter SR (2003) Scenario planning: a tool for conservation in an uncertain world. Conserv Biol 17(2):358-366

Roudier P, Sultan B, Quirion P, Berg A (2011) The impact of future climate change on West African crop yields: what does the recent literature say? Glob Environ Change 21(3):1073-1083

Salter J, Robinson J, Wiek A (2010) Participatory methods of integrated assessment - a review. Wiley Interdiscip Rev Clim Change 1(5):697-717
Sanogo S, Fink AH, Omotosho JA, Ba A, Redl R, Ermert V (2015) Spatio-temporal characteristics of the recent rainfall recovery in West Africa. Int J Climatol 35(2015):4589-4605

Schlenker W, Lobell DB (2010) Robust negative impacts of climate change on African agriculture. Environ Res Lett 5(1):014010

Schmitt Olabisi L (2010) The system dynamics of forest cover in the developing world: researcher vs. community perspectives. Sustainability 2(6): $1523-1535$

Schmitt Olabisi L, Kapuscinski AR, Johnson KA, Reich PB, Stenquist B, Draeger KJ (2010) Using scenario visioning and participatory system dynamics modeling to investigate the future: lessons from minnesota 2050. Sustainability 2(8):2686-2706

Stave KA (2002) Using system dynamics to improve public participation in environmental decisions. Syst Dyn Rev 18(2):139-167

Todd MC, Washington R, Cheke RA, Kniveton D (2002) Brown locust outbreaks and climate variability in southern Africa. J Appl Ecol 39:31-42

Van den Belt M (2004) Mediated modeling: a system dynamics approach to environmental consensus building. Island Press, Washington

Vervoort JM, Thornton PK, Kristjanson P, Förch W, Ericksen PJ, Kok K, Ingram JSI, Herrero M, Palazzo A (2014) Challenges to scenario-guided adaptive action on food security under climate change. Glob Environ Change 28:383-394

Webber AD, Hill CM (2014) Using participatory risk mapping (PRM) to identify and understand people's perceptions of crop loss to animals in Uganda. PLoS One 9(7):e102912

World Bank (2017) World Bank Open Data. Retrieved 16 March 2017, from https://data.worldbank.org/

Yu M, Wang G, Pal JS (2016) Effects of vegetation feedback on future climate change over West Africa. Clim Dyn 46(11):3669-3688

Zhou Y, Staatz J (2016) Projected demand and supply for various foods in West Africa: implications for investments and food policy. Food Policy 61:198-212 